\title{
Acceptability and Compliance to a 10-Day Regimen of Zinc Treatment in Diarrhea in Rural Bangladesh*
}

\author{
Shahnawaz Ahmed ${ }^{1}$, Dilruba Nasrin ${ }^{2}$, Farzana Ferdous ${ }^{1}$, Fahmida Dil Farzana ${ }^{1}$, Guddu Kaur ${ }^{3}$, \\ Mohammod Jobayer Chisti ${ }^{1}$, Sumon Kumar Das ${ }^{1 \#}$, Abu Syed Golam Faruque ${ }^{1}$ \\ ${ }^{1}$ International Centre for Diarrheal Disease Research, Dhaka, Bangladesh; ${ }^{2}$ Centre for Vaccine Development (CVD), University of \\ Maryland School of Medicine, Baltimore, USA; ${ }^{3}$ University of Sydney, Sydney, Australia. \\ Email: shahnawz@icddrb.org, dnasrin@medicine.umaryland.edu, farzanaf@icddrb.org, fahmidaf@icddrb.org, \\ kau887@uni.sydney.edu.au, chisti@icddrb.org, ${ }^{\#}$ sumon@icddrb.org, gfaruque@icddrb.org
}

Received January $7^{\text {th }}, 2013$; revised February $7^{\text {th }}, 2013$; accepted February $14^{\text {th }}, 2013$

Copyright (C) 2013 Shahnawaz Ahmed et al. This is an open access article distributed under the Creative Commons Attribution License, which permits unrestricted use, distribution, and reproduction in any medium, provided the original work is properly cited.

\begin{abstract}
We hypothesised that the promotion of blister packs of zinc may be carried out by health personnel in health care facilities to the mothers of children suffering from diarrhea. We predicted that good acceptability and good compliance to zinc treatment in rural Bangladesh would be over $75 \%$ and at least $60 \%$, respectively. Between January and December 2011, six hundred and thirty five children aged 6 - 59 months who presented with acute diarrhea received a 10-day zinc regimen. Determination of acceptability and compliance of a dispersible zinc tablet in children 6 - 59 months old was main point of the study. In-home follow-ups started within 2 - 3 weeks after the regimen began. Seventy seven percent of the mothers/caretakers perceived that the taste of the zinc tablets was the same or better than that of other medicines given to their children and expressed willingness to use zinc in the future (good acceptability). Sixty-two percent of the children completed full 10-day course of zinc treatment by taking one tablet a day that had been completely dissolved in a small amount of water (good compliance). There was $63 \%$ excess risk for poor compliance to zinc if father stays at home with the family [OR $=1.63(95 \% \mathrm{CI} ; 1.09,2.46) \mathrm{p}=0.019]$. Despite vomiting, $33 \%$ children continued to receive zinc tablet $[\mathrm{OR}=0.67(95 \% \mathrm{CI} ;(0.47,0.97,0.032)]$ after adjusting for co-variates. Both acceptability and compliance to dispersible zinc tablets in childhood diarrheal illnesses are still not at the expected level in rural Bangladesh.
\end{abstract}

Keywords: Acceptability; Compliance; Diarrhea; Young Children; Zinc

\section{Introduction}

The World Health Organization (WHO) and the United Nations Children's Fund (UNICEF) have advocated a 10 14 day course of zinc treatment along with oral rehydration salt solution (ORS) for the treatment of acute childhood diarrhea. Studies have indicated that zinc supplementation is a simple, acceptable, and affordable strategy for managing acute diarrhea and preventing subsequent growth faltering [1,2]. Zinc interventions in children are associated with reduced rates of diarrhea and pneumonia, which are the leading causes of death in children in developing countries [3,4]. Zinc supplemen-

\footnotetext{
*Conflict of interest: There is no potential conflict of interest to declare. All authors state that they do not have professional affiliations or financial agreements with any company, and they are not involved with any product that figures prominently in the submitted manuscript.

${ }^{\#}$ Corresponding author.
}

tation reportedly increases serum levels of zinc in infants with acute diarrhea and has been shown to improve growth during hospitalization in Bangladesh [5,6]. Moreover, weight faltering has not been observed in children with persistent diarrhea who received zinc treatment [7]. One study reported a $30 \%$ greater net length gain compared to controls during an 8-week follow-up period (18.9 mm vs. $14.5 \mathrm{~mm}, \mathrm{p}<0.05$ ) [2]. In addition to reducing growth faltering, zinc supplementation to malnourished children experiencing acute diarrhea also helped decrease morbidities, such as pneumonia, for a subsequent 2-month period [3]. Several researchers have reported that zinc supplementation reduces the duration and severity of acute and persistent diarrhea, $[1,4,8,9]$ including that which occurs due to cholera [10] and shigellosis infections [11].

Zinc is an essential trace element that plays important 
roles in body enzyme systems [12]. Marginal zinc deficiency is common in developing countries, particularly in children who are living in poverty; have low dietary zinc intake; or are exposed to diets rich in phytate, which is known for impeding zinc uptake [13]. Zinc-deficient children are at increased risk for infectious diseases, including diarrhea and pneumonia [14]. The possible mechanisms for the effect of zinc supplementation on diarrhea include improved intestinal absorption of water and electrolytes, quicker regeneration of the gut epithelium, increased levels of enterocyte brush border enzymes, and improved immune responses. This is thought to lead to rapid clearance of diarrheal pathogens from the intestine [15].

A meta-analysis of 18 trials with a total of 6165 participants found that zinc in acute diarrhea results in a shorter duration of diarrhea and less diarrhea on days 3, 5, and $7(31 \%, 45 \%$ and $29 \%)$ compared to controls, respectively. Moreover, none of the trials reported any serious adverse events, although vomiting was more common in zinc-treated children with acute diarrhea [13]. These effects may be attributable to zinc's role in the immune system; zinc deficiency can render individuals more susceptible to bacterial and viral infections [16].

Zinc products (tablet or suspension) manufactured by various pharmaceutical companies are well known in Bangladesh. These preparations are promoted as improving child health and development. Zinc is administered as an adjunct therapy with ORS to replace zinc that is lost in the course of an illness. In an attempt to evaluate acceptability and adherence to a dispersible zinc tablet formulation, a previous community-based cohort study enrolled 303 Bangladeshi children between 6 and 59 months old. Blister packs containing 10 tablets were obtained from selected pharmacies (five rural and five urban) provided by sales officers of the Social Marketing Company (SMC) and distributed to the children's parents. A home visit was made 2 - 3 weeks later to assess acceptability of and adherence to the zinc treatment. Overall, the formulation was acceptable to the children, and $56 \%$ completed the full 10-day course. The adherence rates did not differ by age or sex [17].

However, information about the current acceptability of and compliance to dispersible zinc tablets prescribed in the health facility among children (6 - 59 months old) with diarrheal illnesses, and the motivation of their mothers to administer zinc tablets for consecutive 10 days [18], are lacking, especially in rural areas.

The present study aimed to determine the acceptability of and compliance to a dispersible zinc tablet formulation by a cohort of children 6 - 59 months old who presented to the diarrheal disease unit of a large tertiary level hospital in rural Bangladesh. We hypothesised that blister packs of zinc could be promoted by health personnel, who could distribute them to mothers who bring their children suffering from diarrhea to health clinic facilities. We predicted that the good acceptability and good compliance to zinc treatment in rural Bangladesh would be over $75 \%$ and at least $60 \%$, respectively.

\section{Materials and Methods}

\subsection{Study Design}

We implemented a cohort study of children who were enrolled when they were brought to a health facility due to diarrhea. These children were followed-up at home within 2 - 3 weeks after beginning zinc supplementation.

\subsection{Study Site}

The study site was located approximately 40 miles northwest of Dhaka, the capital city, in the rural community of Mirzapur, a sub-district within the Tangail district that has a population of over 263,000 . The economy of the area is mostly agriculture-based. The International Centre for Diarrheal Disease Research, Bangladesh (icddr,b) has established a Demographic Surveillance System (DSS) in this sub-district (Updated DSS information: June, 2011) for collecting longitudinal information on vital events, such as births, deaths, marriages, and migrations. Eleven percent of the DSS population is comprised of children $<5$ years of age, each of them have a unique DSS identity number. Starting in January 2010, icddr,b has collaborated with Kumudini Hospital to establish a hospitalbased diarrheal disease surveillance system to understand the aetiologic agents that commonly causes diarrhea and their disease burden in the rural community.

\subsection{Sample Size}

In absence of sufficient research literature to facilitate sample size calculation, we assumed a $6 \%$ minimal difference in compliance to zinc tablet among children aged 6 - 59 months old with an anticipated $65 \%$ compliance (p), a 95\% confidence interval $(z=1.96)$, a design effect of 2.3 , and to adjust for likely drop-outs $(10 \%)$, the calculated sample size was $\sim 635$ children.

\subsection{Study Implementation}

All under 5 years old children irrespective of sex and socio-demographic characteristics who visited the rural tertiary level hospital with acute diarrhea. Of them, children aged 6 - 59 months of age, resided in the DSS catchment area were invited to participate. Among them, who voluntarily participated and gave informed written consent and able to provide adequate amount (at least 3 $\mathrm{gm} / \mathrm{ml}$ ) of stool for laboratory detection of common pathogens were finally included into the study. Thus, a 
total of 635 children were enrolled between January and December of 2011. Mothers/caregivers were given one blister packet containing 10 zinc tablets $(20 \mathrm{mg} / \mathrm{tablet})$ and advised to administer one tablet each day for consecutive 10 days. The mothers received counselling on how to prepare dispersible zinc tablets in a teaspoon of water. They were told that a follow-up visit will be made and advised to keep unused "pills" and used blister pack at home. Thus, data were also collected by a home-based follow-up visit within 2 - 3 weeks after beginning daily zinc administration. Information was collected at the health facility and household by trained research assistants who administered a field-tested questionnaire. All enrolled children were clinically assessed, and their level of dehydration and disease severity were determined by the attending physicians following standard WHO guidelines. In addition, weight, length/height, and mid-upper arm circumference (MUAC) were measured at the time of discharge following standard procedures.

\section{Zinc Formula and Preparation Procedure}

Each blister packet of zinc had 10 dispersible zinc tablets. Each tablet contained $20 \mathrm{mg}$ Zinc Sulfate Monohydrate USP equivalent to Zinc $20 \mathrm{mg}$. Each tablet was advised to be dissolved in small amount of water (less than 1 tea spoon full) and administered to the child with diarrhea each day for ten consecutive days.

\subsection{Anthropometric Measurement}

The length/height, weight, and mid-upper arm circumference (MUAC) were measured for each enrolled child. Length/height and MUAC were measured thrice. Methods adapted from How to Weigh and Measure Children: Assessing the Nutritional Status of Young Children in Household Surveys, United Nations Department of Technical Cooperation for Development and Statistical Office, 1986. The length of children $0-23$ months of age were measured (to the nearest $0.1 \mathrm{~cm}$ ) in the recumbent position using a board with a fixed head and sliding foot piece. For children 24 months and older who could stand alone, a standing height was measured (to the nearest 0.1 $\mathrm{cm}$ ). Weight was measured to the nearest $0.1 \mathrm{~kg}$ using a scale that was calibrated daily. Each of the indices was expressed in standard deviation units (SD) from the median of the NCHS/CDC/WHO International Reference Population.

\subsection{Data Analysis}

Data entry and analyses were performed using Statistical Package for Social Sciences (SPSS) for Windows (Version 15.2; Chicago, IL, USA). Descriptive and analytic methods were followed for data analysis. We performed multiple regression analyses to identify factors that were associated with good acceptability and good compliance to zinc treatment. Age of the child, gender, years of schooling of mothers/caretakers, father's stay at home, height-for-age, duration of diarrhea, dysentery, stool frequency, dehydration, vomiting, fever, cough, antibiotic treatment at home during diarrhea, ORS and zinc intake at home, and etiologic agents were included in the model.

\subsection{Definitions}

Acceptability: Acceptability was assessed on the basis of mothers' observation of their children's behaviour when they were given the dispersible zinc preparation. Specifically, the mothers were asked about their perception of the taste of the zinc tablet given to their children compared to other medicines (the three options were: better, same, or worse) [19]. Good acceptability was defined as perception of the taste of the zinc tablets as same or better and expression of willingness of mothers/caregivers to use zinc tablet in future.

Compliance: Compliance was described in relation to zinc dosage, treatment duration, frequency of daily administration, and tablet preparation (dispersion) [19]. Good compliance was defined as once-a-day intake of a 20 - mg zinc tablet that had been completely dissolved in a small amount of water in a teaspoon for 10 consecutive days. Such good compliance was ascertained on the basis of "pill count".

Diarrhea: Diarrhea was defined as three or more loose, liquid, or watery stools or at least one loose stool containing blood in a 24-hour period.

According to WHO growth standards, children were considered malnourished (without pedal oedema) if one of the following statistical conditions were met [20,21]:

Underweight: $<-2$ weight-for-age $z$-score.

Wasting: $<-2$ weight-for-height $z$-score.

Stunting: $<-2$ height-for-age $z$-score.

\subsection{Ethical Consideration}

This analysis among children 6 - 59 months old was part of a diarrheal disease etiology and burden study which was approved by the Research Review Committee and the Ethical Review Committee of icddr,b. Written, informed consent was obtained from the parent or primary caretaker of the child with diarrhea who meets all eligibility criteria. The original signed/imprinted form was retained at the site and the parent or primary caretaker was given a copy to keep and primary caretaker/mother was briefed about the benefit of the study and advised to report to the facility or visit a local health care provider in case the child develops too frequent vomiting.

\section{Result}

The mean \pm standard deviation $(\mathrm{SD})$ of MUAC was 
$14.16 \pm 1.16 \mathrm{~cm}$. Almost all study children had access to safe drinking water (from tube wells). The father's occupation was most reported as overseas employment (22\%), followed by businessman (20\%), farmer $(18 \%)$, and skilled worker (12\%). In $93 \%$ of children, diarrheal illnesses lasted for a week or less (data not presented). Nearly two-thirds $(63 \%)$ of the study children correctly received the full 10-day course of zinc treatment; whereas $98 \%$ of them followed the correct procedure to dissolve the tablet. Ninety-five percent of mothers/caretakers perceived that zinc tablet taste was the same or better than that of other medicines given to their children. Seventy-nine percent of mothers/caretakers stated that they would willingly use zinc to treat their children during future diarrhea episodes. Seventy-seven percent of the primary caretakers reported that the taste of zinc tablet was same or better than other medicines given to their children and they were willing to use zinc to treat their children during diarrhea episodes in future (good acceptability). Sixty-two percent of the children completed the full 10 - day course of zinc treatment; one tablet a day, that had been completely dissolved in a small amount of water (good compliance) (Table 1). Among the diarrheal children, overall duration of diarrhea before coming to health facility was 40 hours. Moreover, zinc use at household level did not influence the prior duration at home before coming to the hospital.

Table 1. Acceptability of and compliance to zinc treatment of the study children, January-December 2011, Mirzapur, rural Bangladesh.

\begin{tabular}{|c|c|}
\hline Outcome & $\mathrm{N}=635(\%)$ \\
\hline \multicolumn{2}{|l|}{ Compliance } \\
\hline $\begin{array}{l}\text { Treated with zinc as prescribed } 1 \\
\text { tablet each day for } 10 \text { days }\end{array}$ & $399(63)$ \\
\hline $\begin{array}{l}\text { Followed correct procedure to } \\
\text { dissolve the tablet }\end{array}$ & $625(98)$ \\
\hline Good compliance & $394(62)$ \\
\hline \multicolumn{2}{|l|}{ Acceptability } \\
\hline \multicolumn{2}{|c|}{ Taste perceived by caretakers } \\
\hline Same as other medicines & $473(74)$ \\
\hline Better than other medicines & $131(21)$ \\
\hline Worse than other medicines & $8(1)$ \\
\hline Don't know & $23(4)$ \\
\hline \multicolumn{2}{|c|}{ Willingness to use zinc tablet in future } \\
\hline Willing & $505(79)$ \\
\hline Not willing/depends & $126(20)$ \\
\hline Don't know & $4(0.6)$ \\
\hline Good acceptability & $486(77)$ \\
\hline
\end{tabular}

However, those who received neither ORS, zinc, nor antimicrobials, presented to the facility significantly earlier $(p<0.001)$ than others (Table 2). The subject demographics indicate that, of the 635 study children, $62 \%$ were male, $79 \%$ were aged $6-23$ months, and the rest were 24 - 59 months old. Ten percent of the respondents had no formal schooling. Twenty-two percent of study children were underweight, $13 \%$ stunted, and $14 \%$ wasted. Ninety-three percent of the subjects had no sign of dehydration on presentation. Forty-six percent of children suffered from fever, and another $43 \%$ had experienced coughing since illness onset (Tables 3 and 4). Those who received zinc before coming to health facility; of them, $67 \%$ had good compliance and $76 \%$ had good acceptability (data not presented). There were $63 \%$ excess risk for poor compliance to zinc if father stays at home with the family [OR $=1.63(95 \% \mathrm{CI} ; 1.09,2.46)$, $\mathrm{p}$ $=0.019$ ] (Table 4). Despite vomiting, 33\% children continued to receive zinc tablet $[\mathrm{OR}=0.67(95 \% \mathrm{CI} ;(0.47$, $0.97,0.032$ )] after adjusting for co-variates (Table 4).

\section{Discussion}

Zinc in tablet or suspension is available as water-soluble sulphate, gluconate, or acetate zinc salts $[22,23]$. The most widely used is zinc sulphate because it is the least expensive. Zinc suspensions are less stable, and proper storage of these suspensions is more difficult in developing countries [24,25]. For this reason, a dispersible zinc tablet formulation (zinc sulphate monohydrate equivalent to $20 \mathrm{mg}$ zinc) has been developed in Bangladesh taking into account: taste; cost; convenience of storage; and distribution. Because dispersible tablets are water sensitive, blister packing is considered to be the most suitable packaging option [19]. The zinc tablets completely disintegrate in a small volume of water in less than 1 minute.

Table 2. Treatment received by the children at home prior to coming to health facility, January-December 2011, Mirzapur, rural Bangladesh.

\begin{tabular}{ccc}
\hline Indicators & $\begin{array}{c}\mathrm{n}(\%) \\
\mathrm{n}=635\end{array}$ & $\begin{array}{c}\text { Median duration of } \\
\text { diarrhea before } \\
\text { coming to facility (h) }\end{array}$ \\
\hline Only ORS & $203(31.9)$ & 28.0 \\
Only zinc tablet & $6(0.9)$ & 15.5 \\
Only antimicrobials & $9(1.4)$ & 90.0 \\
Both ORS and zinc & $70(11.0)$ & 48.0 \\
Both ORS and antimicrobials & $126(19.8)$ & 48.0 \\
Both zinc and antimicrobials & $4(0.6)$ & 56.0 \\
ORS and zinc and antimicrobials & $132(20.8)$ & 49.0 \\
None & $85(13.3)$ & 24.0 \\
\hline
\end{tabular}


Table 3. Characteristics of children with acceptability of zinc, January-December 2011, Mirzapur, rural Bangladesh.

\begin{tabular}{|c|c|c|c|c|c|}
\hline Variable & $\begin{array}{l}\text { Overall, } \\
\mathrm{N}=635(\%)\end{array}$ & $\begin{array}{c}\text { Poor } \\
\text { acceptability, } \\
n=149(23 \%)\end{array}$ & $\begin{array}{c}\text { Good } \\
\text { acceptability; } \\
\mathrm{n}=486(77 \%)\end{array}$ & $\begin{array}{l}\text { Unadjusted OR }(95 \% \mathrm{CI}) \\
\text { p-value }\end{array}$ & $\begin{array}{c}\text { Adjusted OR }(95 \% \mathrm{CI}) \\
\text { p-value }\end{array}$ \\
\hline Age (24 - 59 months) & $133(20.9)$ & $38(25.5)$ & $95(19.5)$ & $1.41(0.89,2.22) 0.147$ & $1.59(0.97,2.60) 0.064$ \\
\hline$\%$ Male & 393 (61.9) & $104(69.8)$ & $289(59.5)$ & $1.58(1.04,2.38) 0.029$ & $1.49(0.99,2.24) 0.053$ \\
\hline Maternal illiteracy & $62(9.8)$ & $21(14.1)$ & $41(8.4)$ & $1.78(0.98,3.23) 0.060$ & $1.67(0.91,3.06) 0.099$ \\
\hline Father stays at home & $489(77.0)$ & $121(81.2)$ & $368(75.7)$ & $1.39(0.85,2.26) 0.200$ & $1.32(0.82,2.13) 0.248$ \\
\hline Nutritional status (stunting) & $85(13.3)$ & $17(11.4)$ & $68(14.0)$ & $0.79(0.43,1.44) 0.501$ & $0.66(0.36,1.20) 0.174$ \\
\hline Duration of diarrhea ( $>40$ hours; median) & $308(48.5)$ & $75(50.3)$ & $233(47.9)$ & $1.10(0.75,1.62) 0.676$ & $1.34(0.97,1.84) 0.075$ \\
\hline Dysentery or visible blood in stool & $472(74.3)$ & $109(73.2)$ & $363(74.7)$ & $1.08(0.70,1.67) 0.788$ & $0.96(0.56,1.63) 0.867$ \\
\hline $\begin{array}{l}\text { Number of stool in last } 24 \text { hours } \\
\quad(\geq 10 \text { times; median value })\end{array}$ & $304(47.9)$ & $70(47.0)$ & $234(48.1)$ & $0.95(0.65,1.40) 0.087$ & $1.02(0.68,1.52) 0.941$ \\
\hline \multicolumn{6}{|c|}{ Clinical features (multiple response) } \\
\hline Some-severe dehydration & $42(6.6)$ & $6(4.0)$ & $36(7.4)$ & $1.91(0.75,5.15) 0.206$ & $0.58(0.23,1.45) 0.245$ \\
\hline Vomiting & $363(57.1)$ & $89(59.7)$ & $274(56.4)$ & $1.15(0.78,1.70) 0.529$ & $1.17(0.76,1.78) 0.475$ \\
\hline Fever & $294(46.3)$ & $64(43.0)$ & $230(47.3)$ & $0.84(0.57,1.23) 0.399$ & $0.76(0.51,1.13) 0.174$ \\
\hline Cough & $271(42.7)$ & $68(45.6)$ & $203(41.8)$ & $1.17(0.80,1.72) 0.459$ & $1.17(0.80,1.72) 0.423$ \\
\hline $\begin{array}{l}\text { Antibiotic administered before } \\
\text { coming to hospital }\end{array}$ & $271(42.7)$ & $73(49.0)$ & $198(40.7)$ & $1.40(0.95,2.05) 0.091$ & $0.75(0.49,1.15) 0.192$ \\
\hline ORS intake before coming to the hospital & $531(83.6)$ & $129(86.6)$ & $402(82.7)$ & $1.35(0.77,2.36) 0.323$ & $0.77(0.42,1.38) 0.376$ \\
\hline Zinc intake before coming to the hospital & $212(33.4)$ & $50(33.6)$ & $162(33.3)$ & $1.01(0.67,1.52) 0.961$ & $1.09(0.70,1.68) 0.715$ \\
\hline \multicolumn{6}{|c|}{ Etiologic agents } \\
\hline Rotavirus & $223(35.1)$ & 49 (32.9) & $174(35.8)$ & $0.88(0.58,1.32) 0.579$ & $0.85(0.54,1.36) 0.504$ \\
\hline Shigella & $71(11.2)$ & $18(12.1)$ & $53(10.9)$ & $1.12(0.61,2.05) 0.802$ & $1.02(0.54,1.91) 0.958$ \\
\hline Vibrio cholerae & $11(1.7)$ & $3(2.0)$ & $8(1.6)$ & $1.23(0.25,5.16) 0.725$ & $1.28(0.31,5.27) 0.728$ \\
\hline ETEC & $18(2.8)$ & $4(2.7)$ & $14(2.9)$ & $0.93(0.25,3.08) 1.00$ & $0.89(0.27,2.95) 0.855$ \\
\hline
\end{tabular}

Dependent variable (Acceptability of zinc, $0=$ Good acceptability, 1 = Poor acceptability).

Mothers are given 10-tablet blister packs and instructed to give one dissolved tablet to children with diarrhea each day for 10 consecutive days [26]. They are specifically instructed to ensure that the child swallows the entire contents of the teaspoon [27].

In the present study, $62 \%$ of the children completed the full 10-day course of properly dissolved zinc tablets (20 mg elemental zinc) as advised (1 tablet a day) (good compliance). A previous study in Bangladesh reported that only $56 \%$ of children completed a 10 -day course of daily zinc tablets from drug stores [17]. This may indicate that the compliance to zinc in children with diarrhea is increasing. This could be explained by several factors. First, there is an overall increase in maternal literacy, which may reflect improved knowledge and awareness of mothers/caregivers about the benefits of zinc tablets for childhood diarrhea. Second, mass media campaigns have increased the general public's overall awareness about zinc for diarrheal illnesses. Third, there is strong networking between health services of Government of Bangladesh (GOB) and local non-governmental organisations to promote zinc treatment for childhood diarrheal illnesses. Fourth, zinc formulations are available at relatively cheap prices, even in remote areas of Bangladesh. Lastly, there is an overall increase in understanding of the importance of managing acute diarrhea with ORS and zinc supplementation. In the current study, zinc was provided to the mothers/caregivers for free. This could have influenced zinc treatment compliance rates. According to a contingent valuation survey in rural Bangladesh, 92\% of the households stated they were willing to pay US\$ 0.26 for a 10 -count blister pack of zinc tablet, and $85 \%$ of respondents with positive attitude expressed a willingness to pay US\$ 0.34 . Only $1 \%$ of the mothers indi- 
Table 4. Characteristics of children with compliance of zinc, January-December 2011, Mirzapur, rural Bangladesh.

\begin{tabular}{|c|c|c|c|c|c|}
\hline Variable & $\begin{array}{l}\text { Overall, } \\
\mathrm{N}=635(\%)\end{array}$ & $\begin{array}{l}\text { Poor compliance; } \\
\mathrm{n}=241(38 \%)\end{array}$ & $\begin{array}{l}\text { Good compliance; } \\
\mathrm{n}=394(62 \%)\end{array}$ & $\begin{array}{l}\text { Unadjusted OR }(95 \% \mathrm{CI}) \\
\text { p-value }\end{array}$ & $\begin{array}{c}\text { Adjusted OR }(95 \% \mathrm{CI}) \\
\text { p-value }\end{array}$ \\
\hline Age (24 - 59 months) & $133(20.9)$ & $56(23.2)$ & $77(19.5)$ & $1.25(0.83,1.87) 0.312$ & $1.27(0.82,1.97) 0.281$ \\
\hline$\%$ Male & $393(61.9)$ & $155(64.3)$ & $238(60.4)$ & $1.18(0.84,1.67) 0.368$ & $1.21(0.86,1.71) 0.272$ \\
\hline Maternal illiteracy & $62(9.8)$ & $22(9.1)$ & $40(10.2)$ & $0.89(0.50,1.59) 0.776$ & $0.77(0.43,1.38) 0.390$ \\
\hline Father stays at home & $489(77.0)$ & $197(81.7)$ & $292(74.1)$ & $1.56(1.03,2.37) 0.033$ & $1.63(1.09,2.46) 0.019$ \\
\hline Nutritional status (stunting) & $85(13.3)$ & $32(13.3)$ & $53(13.5)$ & $0.99(0.60,1.62) 0.954$ & $0.88(0.53,1.44) 0.603$ \\
\hline $\begin{array}{l}\text { Duration of diarrhea } \\
\text { ( }>40 \text { hours; median) }\end{array}$ & $308(48.5)$ & $116(48.1)$ & $192(48.7)$ & $1.06(0.73,1.55) 0.812$ & $0.97(0.72,1.30) 0.816$ \\
\hline Dysentery or visible blood in stool & $472(74.3)$ & $67(27.8)$ & $96(24.4)$ & $1.20(0.82,1.75) 0.385$ & $1.15(0.73,1.82) 0.542$ \\
\hline $\begin{array}{l}\text { Number of stool in last } 24 \text { hours } \\
\quad(\geq 10 \text { times; median value) }\end{array}$ & $304(47.9)$ & $114(47.3)$ & $190(48.2)$ & $0.96(0.69,1.35) 0.885$ & $1.00(0.71,1.42) 0.988$ \\
\hline \multicolumn{6}{|c|}{ Clinical features (multiple response) } \\
\hline Some-severe dehydration & $42(6.6)$ & $17(7.1)$ & $25(6.4)$ & $1.12(0.56,2.20) 0.853$ & $1.09(0.56,2.13) 0.804$ \\
\hline Vomiting & $363(57.1)$ & $125(51.9)$ & $238(60.4)$ & $0.71(0.50,0.99) 0.042$ & $0.67(0.47,0.97) 0.032$ \\
\hline Fever & $294(46.3)$ & $109(45.2)$ & $185(47.0)$ & $0.93(0.67,1.30) 0.732$ & $0.87(0.62,1.24) 0.447$ \\
\hline Cough & $271(42.7)$ & $108(44.8)$ & $163(41.4)$ & $1.15(0.82,1.61) 0.442$ & $1.18(0.84,1.64) 0.345$ \\
\hline $\begin{array}{l}\text { Antibiotic administered before } \\
\text { coming to hospital }\end{array}$ & $271(42.7)$ & $99(41.1)$ & $172(43.7)$ & $0.90(0.64,1.26) 0.579$ & $1.10(0.76,1.60) 0.610$ \\
\hline $\begin{array}{l}\text { ORS intake before coming } \\
\text { to the hospital }\end{array}$ & $531(83.6)$ & $206(85.5)$ & $325(82.5)$ & $0.80(0.50,1.27) 0.380$ & $0.64(0.39,1.05) 0.080$ \\
\hline $\begin{array}{l}\text { Zinc intake before coming } \\
\text { to the hospital }\end{array}$ & $212(33.4)$ & $70(29.0)$ & $142(36.0)$ & $1.38(0.96,1.98) 0.084$ & $1.36(0.93,2.00) 0.114$ \\
\hline \multicolumn{6}{|c|}{ Etiologic agents } \\
\hline Rotavirus & $223(35.1)$ & $84(34.9)$ & $139(35.3)$ & $0.98(0.69,1.39) 0.981$ & $1.25(0.84,1.88) 0.274$ \\
\hline Shigella & $71(11.2)$ & $28(11.6)$ & $43(10.9)$ & $1.07(0.63,1.83) 0.885$ & $0.88(0.50,1.52) 0.636$ \\
\hline Vibrio cholerae & $11(1.7)$ & $3(1.2)$ & $8(2.0)$ & $0.61(0.13,2.54) 0.546$ & $0.79(0.20,3.10) 0.731$ \\
\hline ETEC & $18(2.8)$ & $7(2.9)$ & $11(2.8)$ & $1.04(0.36,2.95) 0.870$ & $1.07(0.40,2.87) 0.896$ \\
\hline
\end{tabular}

Dependent variable (Zinc compliance, $0=$ Good compliance, $1=$ Poor compliance).

cated that they were not willing to pay for zinc tablets [27].

In present study, about $84 \%$ of the children received ORS, $33 \%$ took the zinc treatment, and $43 \%$ of children with diarrhea received antibiotics at home before coming to the hospital. Unnecessary use of antibiotics is a fundamental threat for the development of antibiotic resistance. Zinc treatment, along with standard oral rehydration therapy and culturally appropriate health education could significantly reduce the use of antibiotics and other anti-diarrheal drugs $[27,28]$. In rural Nigeria, adherence to a 10 -day zinc supplementation was $76 \%$ despite a very low rate of ORS use $(9 \%)$ and only $32 \%$ of caregivers being aware of the use of zinc in the management of diarrheal disease. An appropriate promotional strategy could increase the combined use of zinc and ORS and could better meet the challenges of home management of childhood diarrhea [29]. Between September 2006 and October 2008, seven repeated surveys were carried out in urban and rural Bangladesh. The authors determined that by 23 months old, approximately $25 \%$ of urban non-slum, $20 \%$ of municipal and urban slum, and $10 \%$ of rural children under 5 years old had received zinc to treat diarrhea. Although the benefits of zinc treatment for childhood diarrhea had been described in a mass media campaign (television and radio messages) and rapidly achieved widespread awareness, actual practice has lagged behind. Disparities in zinc coverage favouring higher income and urban families were identified, but such disparities diminished over the two-year follow-up period; zinc treatment coverage has steadily increased over time among rural and urban slum households [30]. In the current study, $33 \%$ of the study children had taken zinc before coming to the hospital, as opposed to a $10 \%$ 
overall use rate for diarrhea in Bangladesh [30].

In rural Bangladesh, father is often the main decision maker of the household particularly those decisions related to health care seeking. The present study indicated that fathers stay at home was associated with $63 \%$ excess risk for poor compliance to zinc tablets. Therefore, fathers should also be included in any education programmes for promotion of zinc use in diarrheal illnesses. The study has observed positive attitude of mothers to continue with zinc tablets despite vomiting of children. Thus, mothers' role in continuing with zinc therapy despite vomiting should be acknowledged and they should be encouraged in doing so more and more during their participation in education programmes.

The present study relied on mothers/caregivers' responses, and did not collect information regarding health care providers' instructions on methods of preparation of suspension, what dose of zinc to administer, and how long they should give the treatment. We are also unsure if they properly informed the children's caregivers about possible common side effects, such as vomiting and what to do if the child vomits. The present study was conducted in a single site in rural Bangladesh. Thus the findings may not be generalizable to a larger population. Zinc was provided to the mothers free of charge, which might have influenced compliance and acceptability. There were also several strengths to our study: we studied a large number of young children over a year-long period that included seasonal differences. Health professsionals counselled mothers' of children with diarrhea and promoted zinc treatment. Unlike other studies, our participants were visited at home 2 - 3 weeks after beginning the zinc treatment; therefore, we might have collected more accurate and relevant data.

\section{Conclusion}

Greater efforts by various institutions are required to create awareness about the importance and use of zinc by mothers/caregivers and to improve acceptability and compliance to zinc supplementation. The results of this study and others suggest that such efforts might reduce the negative consequences of diarrhea in Bangladeshi children.

\section{Acknowledgements}

This study was funded by icddr,b and its donor, who provide unrestricted support to icddr,b for its operations and research. Among current donors, this study received unrestricted support from the Swedish International Development Cooperation Agency (Sida), and we gratefully acknowledge their support and commitment to icddr,b's research efforts. Our heartfelt thanks go to the Medical Director of Kumudini Hospital for his sincere support of the research team. We sincerely thank Dr. Kamrun Nahar, Dr. Sultana Yeasmin, and Dr. Fahmida Chowdhury for reviewing the manuscript and providing their valuable comments and suggestions.

\section{REFERENCES}

[1] Z. Bhutta, S. Bird, R. Black, K. Brown, J. Gardner, A. Hidayat, F. Khatun, R. Martorell, N. Ninh, M. Penny, J. Rosado, S. Roy, M. Ruel, S. Sazawal and A. Shankar, "Therapeutic Effects of Oral Zinc in Acute and Persistent Diarrhea in Children in Developing Countries: Pooled Analysis of Randomized Controlled Trials," The American Journal of Clinical Nutrition, Vol. 72, No. 6, 2000, pp. 1516-1522.

[2] S. Roy, A. Tomkins, R. Haider, R. Behren, S. Akramuzzaman, D. Mahalanabis and G. Fuchs, "Impact of Zinc Supplementation on Subsequent Growth and Morbidity in Bangladeshi Children with Acute Diarrhoea," European Journal of Clinical Nutrition, Vol. 53, No. 7, 1999, pp. 529-534. doi:10.1038/sj.ejen.1600734

[3] Z. A. Bhutta, R. E. Black, K. H. Brown, J. M. Gardner, S. Gore, A. Hidayat, F. Khatun, R. Martorell, N. X. Ninh, M. E. Penny, J. L. Rosado, S. K. Roy, M. Ruel, S. Sazawal and A. Shankar, "Prevention of Diarrhea and Pneumonia by Zinc Supplementation in Children in Developing Countries: Pooled Analysis of Randomized Controlled Trials. Zinc Investigators' Collaborative Group," The Journal of Pediatrics, Vol. 135, No. 6, 1999, pp. 689-697. doi:10.1016/S0022-3476(99)70086-7

[4] W. Brooks, M. Santosham, S. Roy, A. Faruque, M. Wahed, K. Nahar, A. Khan, A. Khan, G. Fuchs and R. Black, "Efficacy of Zinc in Young Infants with Acute Watery Diarrhea," The American Journal of Clinical Nutrition, Vol. 82, No. 3, 2005, pp. 605-610.

[5] Z. A. Bhutta, S. M. Bird, R. E. Black, K. H. Brown, J. M. Gardner, A. Hidayat, F. Khatun, R. Martorell, N. X. Ninh, M. E. Penny, J. L. Rosado, S. K. Roy, M. Ruel, S. Sazawal and A. Shankar, "Therapeutic Effects of Oral Zinc in Acute and Persistent Diarrhea in Children in Developing Countries: Pooled Analysis of Randomized Controlled trials," The American Journal of Clinical Nutrition, Vol. 72, No. 6, 2000, pp. 1516-1522.

[6] K. Brown, J. Peerson, S. Baker and S. Hess, "Preventive Zinc Supplementation among Infants, Preschoolers, and Older Prepubertal Children," Food and Nutrition Bulletin, Vol. 30, No. 1, 2009, pp. S12-S40.

[7] S. Roy, A. Tomkins, D. Mahalanabis, S. Akramuzzaman, R. Haider, R. Behrens and G. Fuchs, "Impact of Zinc Supplementation on Persistent Diarrhoea in Malnourished Bangladeshi Children," Acta Paediatrica, Vol. 87, No. 12, 1998, pp. 1235-1239. doi:10.1111/j.1651-2227.1998.tb00943.x

[8] M. Lukacik, R. Thomas and J. Aranda, "A Meta-Analysis of the Effects of Oral Zinc in the Treatment of Acute and Persistent Diarrhea," Pediatrics, Vol. 121, No. 2, 2008, pp. 326-336. doi:10.1542/peds.2007-0921

[9] B. Haider and Z. Bhutta, "The Effect of Therapeutic Zinc Supplementation among Young Children with Selected 
Infections: A Review of the Evidence," Food and Nutrition Bulletin, Vol. 30, No. 1, 2009, pp. S41-S59.

[10] S. Roy, M. J. Hossain, W. Khatun, B. Chakraborty, S. Chowdhury, A. Begum, S. Mahe-Muneer, S. Shafique, M. Khanam and R. Chowdhury, "Zinc Supplementation in Children with Cholera in Bangladesh: Randomised Controlled Trial," British Medical Journal, Vol. 336, No. 7638, 2008, pp. 266-268. doi:10.1136/bmj.39416.646250.AE

[11] S. Roy, R. Raqib, W. Khatun, T. Azim, R. Chowdhury, G. Fuchs and D. Sack, "Zinc Supplementation in the Management of Shigellosis in Malnourished Children in Bangladesh," European Journal of Clinical Nutrition, Vol. 62, No. 7, 2008, pp. 849-855. doi:10.1038/sj.ejen.1602795

[12] K. Jomova and M. Valko, "Advances in Metal-Induced Oxidative Stress and Human Disease," Toxicology, Vol. 283, No. 2-3, pp. 65-87. doi:10.1016/j.tox.2011.03.001

[13] M. Lazzerini and L. Ronfani, "Oral Zinc for Treating Diarrhoea in Children," Cochrane Database of Systematic Reviews, No. 3, 2008, Article ID: CD005436.

[14] M. K. Bhan, H. Sommerfelt and T. Strand, "Micronutrient Deficiency in Children," British Journal of Nutrition, Vol. 85, No. S2, 2001, pp. S199-S203. doi:10.1079/BJN2001315

[15] K. Jomova and M. Valko, "Advances in Metal-Induced Oxidative Stress and Human Disease," Toxicology, Vol. 283, No. 2-3, 2011, pp. 65-87. doi:10.1016/j.tox.2011.03.001

[16] A. H. Shankar and A. S. Prasad, "Zinc and Immune Function: The Biological Basis of Altered Resistance to Infection," The American Journal of Clinical Nutrition, Vol. 68, No. 2, 1998, pp. S447-S463.

[17] D. Nasrin, C. P. Larson, S. Sultana and T. U. Khan, “Acceptability of and Adherence to Dispersible Zinc Tablet in the Treatment of Acute Childhood Diarrhoea," Journal of Health, Population and Nutrition, Vol. 23, No. 3, 2005, pp. 215-221.

[18] A. M. Khan, C. P. Larson, A. S. Faruque, U. R. Saha, A. B. Hoque, N. U. Alam and M. A. Salam, "Introduction of Routine Zinc Therapy for Children with Diarrhoea: Evaluation of Safety," Journal of Health, Population and Nutrition, Vol. 25, No. 2, 2007, pp. 127-133.

[19] D. Nasrin, C. Larson, S. Sultana and T. Khan, "Acceptability of and Adherence to Dispersible Zinc Tablet in the Treatment of Acute Childhood Diarrhoea," Journal of Health, Population and Nutrition, Vol. 23, No. 3, 2005, pp. 215-221.

[20] Y. Zverev, "Prediction of Peak Expiratory Flow Rates in Stunted Children," Central African Journal of Medicine, Vol. 47, No. 3, 2001, pp. 74-78. doi:10.4314/cajm.v47i3.8598
[21] N. Joshi, T. Rikimaru and S. Pandey, "Effects of Economic Status and Education Level on the Height and Weight of Community Adolescents in Nepal," Journal of Nutritional Science and Vitaminology, Vol. 51, No. 4, 2005, pp. 231-238. doi:10.3177/jnsv.51.231

[22] R. Black, "Therapeutic and Preventive Effects of Zinc on Serious Childhood Infectious Diseases in Developing Countries," The American Journal of Clinical Nutrition, Vol. 68, No. 2, 1998, pp. S476-S479.

[23] Z. Bhutta, R. Black, K. Brown, J. Gardner, S. Gore, A. Hidayat, F. Khatun, R. Martorell, N. Ninh, M. Penny, J. Rosado, S. Roy, M. Ruel, S. Sazawal and A. Shankar, "Prevention of Diarrhea and Pneumonia by Zinc Supplementation in Children in Developing Countries: Pooled Analysis of Randomized Controlled Trials. Zinc Investigators' Collaborative Group," The Journal of Pediatrics, Vol. 135, No. 6, 1999, pp. 689-697. doi:10.1016/S0022-3476(99)70086-7

[24] WHO, "Production of Zinc Tablets and Zinc Oral Solutions," WHO, Geneva, 2007.

[25] A. Khan, C. Larson, A. Faruque, U. Saha, A. Hoque, N. Alam and M. Salam, "Introduction of Routine Zinc Therapy for Children with Diarrhoea: Evaluation of Safety," Journal of Health, Population and Nutrition, Vol. 25, No. 2, 2007, pp. 127-133.

[26] P. Winch, K. Gilroy, S. Doumbia, A. Patterson, Z. Daou, S. Coulibaly, E. Swedberg, R. Black and O. Fontaine, "Prescription and Administration of a 14-Day Regimen of Zinc Treatment for Childhood Diarrhea in Mali," The American Journal of Tropical Medicine and Hygiene, Vol. 74, No. 5, 2006, pp. 880-883.

[27] S. Akhter and C. Larson, "Willingness to Pay for Zinc Treatment of Childhood Diarrhoea in a Rural Population of Bangladesh," Health Policy Plan, Vol. 25, No. 3, 2010, pp. 230-236. doi:10.1093/heapol/czp058

[28] A. H. Baqui, R. E. Black, S. El Arifeen, M. Yunus, K. Zaman, N. Begum, A. A. Roess and M. Santosham, "Zinc Therapy for Diarrhoea Increased the Use of Oral Rehydration Therapy and Reduced the Use of Antibiotics in Bangladeshi Children," Journal of Health, Population and Nutrition, Vol. 22, No. 4, 2004, pp. 440-442.

[29] O. Ogunrinde, T. Raji, O. Owolabi and K. Anigo, "Knowledge, Attitude and Practice of Home Management of Childhood Diarrhoea among Caregivers of under-5 Children with Diarrhoeal Disease in Northwestern Nigeria," Journal of Tropical Pediatrics, Vol. 58, No. 2, 2012, pp. 143-146. doi:10.1093/tropej/fmr048

[30] C. P. Larson, U. R. Saha and H. Nazrul, "Impact Monitoring of the National Scale up of Zinc Treatment for Childhood Diarrhea in Bangladesh: Repeat Ecologic Surveys," PLoS Medicine, Vol. 6, No. 11, 2009, Article ID: e1000175. doi:10.1371/journal.pmed.1000175 